\title{
WITTGENSTEIN E A MEDIDA DA CIRCUNFERÊNCIA
}

\author{
André Porto (UFG) \\ andre.s.porto@uol.com.br
}

Nada é mais fatal para o entendimento filosófico do que a noção de prova e de experiência como dois métodos de verificação distintos, mas comparáveis. (WITTGENSTEIN L. , 2005, p. 419)

Resumo: A filosofia da matemática de Wittgenstein envolve duas teses profundamente controversas: a idéia de que as proposições matemáticas não falam sobre objetos (abstratos) e a idéia de que nenhuma conjectura matemática é jamais respondida como tal, porque o advento da prova sempre determina uma mutação semântica nos significados dos termos envolvidos na conjectura. $\mathrm{O}$ presente artigo oferece uma reconstrução dos argumentos de Wittgenstein em apoio a essas teses em um contexto muito restrito: A descoberta de Arquimedes de um algoritmo para calcular o número Pi.

Palavras-chave: Wittgenstein; filosofia da matemática; continuidade.

\section{INTRODUÇÃO}

Bem no centro da filosofia da matemática de Wittgenstein encontramos duas teses profundamente contra-intuitivas, polêmicas mesmo. Dificilmente a alguém escaparia o enorme potencial subversivo dessas teses: as conseqüências arrasadoras que 
a aceitação de qualquer delas teria para com a maneira como usualmente concebemos a matemática. Vejamos estas propostas tão controversas.

A primeira delas reza que a matemática não fala sobre os objetos matemáticos, aqueles objetos abstratos sobre os quais estamos acostumados a pensar que ela fale. Assim, por exemplo, se perguntássemos a alguém sobre o que versa a afirmação " $2+2$ = 4", seria natural a resposta: "Sobre o número 2 e o número 4!". De fato, a matemática como um todo é normalmente tratada exatamente como a ciência de (certos) objetos abstratos, objetos tais como números, conjuntos, funções, propriedades (algébricas, por exemplo), relações, etc.

Tudo isso é recusado por Wittgenstein. Para o filósofo, imaginar que a matemática trate de objetos abstratos está na raiz de toda a sorte de contra-sensos filosóficos; "absurdos", na terminologia do pensador. Para ele, a sucessão de crises fundacionais pelas quais a matemática passou, pelo menos nos últimos 180 anos, não é muito mais do que uma decorrência previsível da adoção desse ponto de vista inicial "tão enganador".

Para Wittgenstein, a matemática não fala sobre objetos abstratos. Na verdade, para ele, sequer faz sentido se falar em objetos que sejam abstratos. Uma afirmação como " $2+2=4$ " não deveria, segundo o filósofo, ser entendida como afirmando algo a respeito dos números " 2 e " 4 ". " $2+2=4$ " não falaria, nem sobre "2", nem sobre "4"! Chamemos essa tese de "caráter nãopredicativo da matemática" (de fato, todas as "regras" são nãopredicativas, segundo o autor). A evidência textual de que Wittgenstein de fato subscrevia a essa estranha tese é impressionante. Aqui estão uns poucos exemplos, particularmente diretos: 
Proposições matemáticas não tratam sobre números. Enquanto que uma proposição como "Há três janelas nesta sala" efetivamente trata do número 3. (WITTGENSTEIN L 1976, p. 250) Suponha que eu diga "Prince tem umas calças azuis"; Aquela proposição é sobre as calças. (...) E a respeito de "dois"? "2 + 2 = 4" - mas isto não é sobre 2; é gramatical. (WITTGENSTEIN L 1976, p. 250-1)

[...] uma proposição matemática não é sobre seus constituintes no sentido em que "O sofá está na sala" é sobre o sofá. (LFM, palestra XXVI, p. 254)

Isso é um engano dos mais importantes. - É claro que você pode dizer que proposições matemáticas são sobre números. Mas, se você fizer isso, estará quase que certamente entrando em uma confusão. (WITTGENSTEIN L 1976, p. 251)

Deixemos a tese da não-predicatividade das regras de lado. Há uma segunda tese proposta pelo autor, central para toda a sua filosofia, que é pelo menos tão indigesta como a primeira. Estamos nos referindo à idéia de que, em certo sentido, uma demonstração matemática nunca pode ser uma resposta à conjectura que a motivou! De fato, para o filósofo, diferentemente do caso de perguntas empíricas, onde o resultado da investigação de fato responde precisamente à questão levantada nos termos em que ela é proposta, a "resposta" matemática sempre altera $o$ próprio sentido dos termos em que foi formulada a conjectura. Nunca respondemos a uma conjectura matemática, simplesmente porque a demonstração sempre altera o sentido dos próprios termos envolvidos naquela conjectura.

Chamemos essa segunda tese de "mutação semântica das provas". Novamente, a comprovação textual de que o filósofo de fato avançou uma tese desse tipo parece ser incontestável. Assim, por exemplo, em um trecho de seu Big Typescript, o filósofo compara uma pergunta médica (empírica) a uma conjectura matemática. Ele escreve: 
A "prova médica" não incorporava a hipótese provada em um novo cálculo, e assim não lhe dava um novo sentido; uma prova matemática incorpora a proposição matemática em um novo cálculo, e assim altera sua posição na matemática. Uma proposição com sua prova pertence a uma categoria diferente do que uma proposição sem uma prova. (WITTGENSTEIN L. 2005, § 121, p 426)

O filósofo constantemente recusa a idéia de que possamos responder a uma pergunta matemática exatamente nos termos em que a hipótese inicial havia sido formulada. Assim, como ilustração, podemos mencionar suas conhecidas discussões sobre "regularidades matemáticas" (como a recursão do resto de uma divisão periódica, ou o número de soluções de uma equação de grau $n$ ). Na visão ordinária, muitas dessas regularidades teriam sido mais tarde demonstradas:

Algumas vezes parece como se descobertas matemáticas fossem logradas executando-se o que poderíamos chamar de um experimento matemático. Por exemplo, o matemático, primeiro, nota certa regularidade e, depois, prova que aquilo tinha de ser assim. (WITTGENSTEIN L 1976, p. 92)

Como seria de se esperar, ao invés de aceitar a prova como a confirmação da conjectura anterior, o filósofo invariavelmente insiste na idéia de que demonstração teria introduzido um novo cálculo, i.e., sentidos inteiramente novos para os termos originais envolvidos:

A descoberta da periodicidade é realmente a construção de um novo símbolo e de um novo cálculo. Pois é enganador dizer que ela consiste em nós termos nos dado conta de que o primeiro resto era o mesmo que o dividendo. (WITTGENSTEIN L. 2005, § 128, p 451) 
Com respeito ao caso das raízes de uma equação, novamente o filósofo retorna à idéia de uma mutação no sentido dos termos originais da conjectura:

Contamos as raízes de uma equação: como pode a afirmação de que certas equações têm duas raízes, ser uma regra? Direi que ela introduz um novo símbolo em nossos cálculos: a palavra "raiz". Pois não calculamos ordinariamente com a palavra "raiz". (WITTGENSTEIN L 1976, p. 48)

Não pretendemos, em nosso artigo, enfrentar essas duas estranhas teses em toda a sua generalidade (deixaremos isso para um trabalho posterior). Longe disso, nos limitaremos aqui a apresentar uma "reconstrução" antiga (PORTO 1996) sobre uma aplicação dessas idéias a um caso particular na matemática: o cálculo, por Arquimedes, da razão entre o raio e a circunferência de um círculo, do número Pi. Além do interesse em ver como poderia se dar a argumentação de Wittgenstein em favor de suas idéias nesse caso, esta reconstrução nos dará a oportunidade de abordarmos também outro tópico muito importante na filosofia da matemática do autor: seu tratamento das idéias de "continuidade" e de "aproximação matemática".

Um último ponto, antes de darmos início a nossa reconstrução da abordagem wittgensteineana à descoberta de Arquimedes. Como ficará bem claro ao longo de nossa exposição, as duas estranhas teses acima (não-predicatividade das regras e mutação semântica nas demonstrações) não são logicamente independentes uma da outra. De fato, como veremos em detalhes naquele caso particular, é exatamente porque em matemática não falamos sobre objetos que não haverá nada (nenhum “objeto") que possa "ligar” a conjectura à proposição demonstrada. Daí a mutação semântica proposta por Wittgenstein.

Dito de outra forma, na concepção tradicional, falamos, antes e depois da prova, sobre os mesmos objetos. Assim, seriam 
esses objetos que ligam semanticamente a conjectura à prova. E é precisamente por isso que, segundo essa visão tradicional, a prova confirma exatamente o que fora dito antes de sua demonstração: pois estamos falando sobre os mesmos objetos, disponíveis - imutáveis -, antes e depois do advento da prova. Ao recusar a idéia de "objetos abstratos", Wittgenstein abre mão exatamente desse pivô, esses objetos que, segundo a concepção ordinária, ligariam semanticamente os dois momentos: antes e depois da resolução da conjectura. ${ }^{1}$

\title{
QUAL O FEITO DE ARQUIMEDES?
}

\author{
Deveríamos assumir que haviamos \\ medido Pi da mesma maneira que uma \\ constante fisica é medida? Obviamente, \\ não. \\ Nenhuma medição pode nos dizer o \\ valor de $\mathrm{Pi}$ ou entre que valores ele é \\ encontrado, o número Pi é de fato o \\ padrão através do qual julgamos a \\ qualidade de uma medição. \\ (WITTGENSTEIN L. 1979, p. 62)
}

Existe uma maneira natural de se apresentar o feito matemático de Arquimedes, exposto em sua famosa obra Sobre a medição do círculo. Arquimedes teria descoberto o valor de $P i$, ou seja, teria descoberto que $P i$ é igual a $3,1416 \ldots$ Assim, sua contribuição falaria sobre algo, sobre $P i$, entendido como sendo a razão entre o raio e a circunferência do círculo, e estabeleceria que essa razão é igual a $2 \times 3,1416 \ldots$. Podemos tornar nossa apresentação ainda mais concreta esclarecendo o que queremos dizer com a expressão "razão entre a circunferência e o raio de um círculo". Diríamos: estamos nos referindo a algo 
bem palpável, a medida da metade da circunferência de um círculo de raio 1 (1 metro, digamos).

Arquimedes teria, assim, descoberto uma medida. Poderíamos desenhar um círculo de raio igual a, digamos, $10 \mathrm{~cm}$ (para o círculo não ficar muito pequeno) e assim "vermos" exatamente sobre que extensão o geômetra grego estava falando: ele estava se referindo ao comprimento da metade do percurso feito por nosso compasso quando traçamos o círculo. Arquimedes teria encontrado aquela medida, o comprimento daquele segmento à nossa frente, o segmento que acabávamos de traçar. Apenas, para a surpresa de todos, aquela medida seria igual a um número infinito, uma dízima completamente não periódica. É claro que haveria algo de estranho em pensarmos que todos aqueles números, 3,14159265..., estariam de certa forma "lá em nosso pequeno círculo", desenhado na folha de papel, mas ainda assim, a situação permaneceria inalterada. Seria sobre esses segmentos que Arquimedes estaria falando, ele teria encontrado a medida de extensões como essa.

Não é preciso muita argumentação para nos convencermos de que, apresentada dessa maneira, a contribuição de Arquimedes se aproxima muito de uma descoberta empírica. Assim, por exemplo, vamos supor que o automóvel de um vizinho esteja em nossa garagem. Mais tarde descobrimos que esse carro é dotado de transmissão automática. No caso de Arquimedes, como aqui, estaríamos falando sobre uma coisa - $\boldsymbol{o}$ automóvel na garagem, $\boldsymbol{a}$ medida da circunferência de um círculo de raio um - coisa essa que se mantém estável antes e depois da descoberta. Tínhamos um e o mesmo carro em nossa garagem, antes e depois de descobrirmos que ele era dotado de transmissão automática. $\mathrm{Ou}$, dito de forma menos grosseira, tínhamos um conceito de "automóvel-de-nosso-vizinho" e ele não se alterou apenas porque aconteceu de termos descoberto que 
aquele carro tivesse tal tipo de transmissão. Igualmente, no caso de Arquimedes, já tínhamos o (mesmo) conceito de "medida-da-circunferência”, antes e depois de sua contribuição matemática. Já sabíamos medir várias circunferências e, como no caso do automóvel, o conceito dessa medida não teria se alterado apenas por termos descoberto que valor preciso "acontecia ser" igual a $2 \times 3,1416 \ldots$.

A forma de Wittgenstein descrever a contribuição do grande geômetra grego não se dará, é claro, nos mesmos termos em que a apresentamos acima. Como sempre, podemos dividir a estratégia de argumentação do filósofo em duas etapas. Em primeiro lugar ele irá procurar separar cuidadosamente a ocorrência de certos termos (em nosso caso, de termos como "medida", "aproximação") em proposições empíricas de sua ocorrência em proposições matemáticas. Em seguida, procurará argumentar que essas proposições matemáticas de fato estabeleceriam novas regras delimitadoras do sentido de afirmações empíricas, novas regras delimitadoras do emprego de tais proposições, alterando o sentido dos termos componentes da conjectura anterior à prova. Mais precisamente, como veremos no final do artigo, Arquimedes estabelece, segundo Wittgenstein, novas regras a respeito de alegações do tipo "tal medição (empírica) da circunferência do círculo é mais próxima do que tal outra". Assim, em poucas palavras, o trabalho de Arquimedes não falaria, não descobriria nada sobre medições mais exatas de circunferências de círculos porque seria exatamente na alteração do sentido, do uso dessas palavras, que se encontraria o mérito do geômetra.

É difícil, inicialmente, aceitar a sugestão de Wittgenstein. Não parece haver motivo algum para falarmos em "novas regras de uso", muito menos em "novos sentidos" para antigas palavras, como quer o filósofo. Temos os termos "círculo", "cir- 
cunferência", "medida". Todos esses termos já tinham significados bem delineados, os significados que têm (antes ou depois da contribuição de Arquimedes). Deixemos assim, por hora, as propostas de Wittgenstein e voltemos à nossa maneira anterior de encarar a situação: Arquimedes descobriu a medida da circunferência de um círculo de raio 1 . Como frisamos, já tínhamos um significado preciso para a palavra "medir". Já medíamos mesas, terrenos, etc. Por outro lado, conhecíamos os círculos, sabíamos como reconhecê-los e até mesmo como desenhá-los. E sabíamos, é claro, a que segmento nos referíamos pela expressão "circunferência".

Chegamos então ao ponto importante: os três termos não só tinham significado isoladamente, eram usados separadamente, mas até mesmo já eram empregados em conjunto. Já podíamos, antes de Arquimedes, falar e conjecturar sobre qual seria a medida da circunferência de um círculo. Já usávamos os três termos juntos, exatamente no sentido em que os usamos agora. Assim, Arquimedes teria respondido a uma pergunta definida, uma pergunta dizendo respeito a essa medida. Teria descoberto que ela era igual a $2 \times 3,1416 \ldots$. Aí se encontraria a maior vantagem de nossa proposta inicial de abordagem do feito do matemático grego. Com ela podemos como que "apontar" para exatamente qual teria sido a contribuição de Arquimedes, antes que ela tivesse se dado. O Geômetra grego teria respondido a pergunta sobre qual seria a medida da circunferência de um círculo de raio um. Queríamos saber algo, e ele nos respondeu. Estaria aí o seu mérito.

Vejamos com mais cuidado, no entanto, essa questão que teria sido respondida por Arquimedes. Qual o significado de se perguntar pela medida da circunferência de um círculo antes de Arquimedes? De uma forma bem direta, simples e primitiva, poderíamos argumentar que, mesmo antes da obra do ge- 
ômetra grego, sabíamos como desenhar um círculo. Uma vez de posse desse círculo, poderíamos tomar, digamos, um barbante, cortá-lo do tamanho do raio e, com todo o cuidado, medir quantas vezes esse caberia na circunferência. Estaríamos efetivamente medindo a circunferência do círculo de raio 1 , (exatamente a mesma coisa que teria sido feita, mais tarde, por Arquimedes). De fato, antes mesmo de executarmos tal medição, já poderíamos antecipar certas coisas sobre a tal medida: $\mathrm{Pi}$ teria necessariamente de ser menor do que, digamos, 15! Claramente a circunferência não é 15 vezes maior do que o seu raio. Assim, contrariamente ao que sugere Wittgenstein, não parece ter havido nenhuma alteração nos sentidos das palavras "medição da circunferência do círculo". Já fazíamos isto antes de Arquimedes, sua contribuição tendo sido apenas, digamos, a descoberta de um "método mais... preciso".

\section{DOIS TIPOS DE CÍRCULOS: IDEAIS E EMPÍRICOS}

Retomaremos, neste ponto, a argumentação de Wittgenstein: em que sentido Arquimedes teria feito a mesma coisa que alguém que lançasse mão do "método do barbante" que descrevemos acima? Afirmamos que os dois estariam "medindo a circunferência do círculo". Aqui começam a aparecer as dificuldades de tentarmos aproximar o feito de Arquimedes daquele obtido por nosso fulano com a ajuda de seu barbante. Os dois estariam medindo um círculo ou o circulo? A alguém que tivesse acabado de executar uma medição empírica de um círculo, poderíamos claramente perguntar: "Exatamente que círculo você usou para fazer sua medição?" Duas pessoas, ainda que usassem o mesmo método do barbante, mas que medissem dois círculos muito diferentes, digamos, um muito maior do que o outro, encontrariam certamente resultados igualmente diversos. E poderíamos até mesmo chegar a descobrir que a 
figura utilizada por uma dessas pessoas, apesar de parecer com um círculo, estava de fato mal desenhada, não era um círculo.

Mais do que isto, podemos até mesmo distinguir medidas de um mesmo círculo executadas em tempos diferentes e por pessoas diferentes. Podemos dizer que a medida executada essa manhã por fulano é diferente da de beltrano, ainda que ambos tivessem usado o mesmo círculo. Assim, no caso de uma medição em seu sentido empírico, nunca conseguimos "libertar-nos completamente" da referência a um círculo específico (aquele que foi usado na medição), de um agente executor (dessa medição) e sequer de uma referência temporal, a ocasião específica em que aquela operação se deu. $\mathrm{O}$ mais adequado seria talvez afirmar que, quando alguém executa a medição usando um barbante, ou qualquer outro método empírico de medição, esta medição é realizada com respeito a um círculo específico em uma ocasião específica.

No caso da operação "medição matemática do círculo" levada a cabo pelo geômetra grego, o que diríamos? Faria sentido, como fazíamos na situação empírica, perguntarmos quando exatamente Arquimedes executou sua medida, ou quantas vezes ele a executou? Nessa "medição matemática", precisaríamos saber também qual exatamente teria sido o círculo por ele medido? Teria Arquimedes logrado medir a circunferência de apenas um círculo (o círculo por ele empregado)? Em outras palavras, poderia haver outro círculo com uma medida diferente para a sua circunferência? Estaríamos dispostos a aceitar a possibilidade de alguém, mais tarde, descobrir (através de uma medição mais precisa) um círculo para o qual a medida de Arquimedes falhasse? Wittgenstein escreve:

Suponha que em uma medição encontrássemos valores diferentes para a razão entre o raio e a circunferência. - Deveríamos então dizer que delimitamos o número $\mathrm{Pi}$ em intervalos diferen- 
tes? [...] Obviamente não. Pois se todos aqueles intervalos acontecessem de ser grandes demais, não suporíamos que o valor de Pi era maior, mas diríamos que tínhamos cometido um erro. (1979, p. 61-2)

Existe uma maneira de tentarmos minimizar o fosso que ameaça abrir-se entre os dois sentidos da palavra "medir" atribuindo a diferença toda ao "objeto" das medições. Assim, diríamos que Arquimedes não teria medido "nenhum círculo em especial", mas os "círculos em geral", ou talvez, pior ainda, que teria medido um "círculo ideal". Começaríamos assim a reconhecer alguma diferença entre dizermos que "Arquimedes mediu o círculo" e que "fulano mediu o círculo (com um barbante)", mas trataríamos essa diferença como sendo a de dois "objetos de medida diferentes", um "real”, outro "ideal”. Também isso traria problemas. Que relação guardam entre si os dois objetos medidos, o "círculo ideal" e o "círculo real"? O que teria a ver (a medição de) um círculo-ideal com um círculoempírico? Não se trata, é claro, de duas acepções completamente não relacionadas, como no caso da medição de um "cabo-de-panela" e de um "cabo-geográfico".

Wittgenstein não nega que haja uma relação entre o que fez Arquimedes e o que faz alguém que lança mão de um barbante para medir um círculo. $\mathrm{O}$ problema está exatamente em determinar exatamente qual é essa relação. Antes, nos pareceu natural descrevê-la como duas instâncias de "medições de círculos". Porém os dois usos da palavra "medição" não parecem ser realmente equivalentes. E aqui o filósofo não se cansa de nos advertir contra a idéia de tentarmos salvar a analogia entre essas duas "medições", apoiados apenas em uma distinção do objetos a serem medidos em cada uma delas ("objetos reais", "objetos ideais"). Ou seja, a estratégia de insistirmos na identidade de sentidos para as duas "mensurações" e resolver nossos 
problemas postulando um "novo tipo de círculo", um "círculo ideal”.

A solução de Wittgenstein, como sempre, é insistir que o que distinguiria os dois tipos de proposições não seriam os objetos a que elas se referem - objetos ideais e objetos reais - mas, sim, o caráter normativo das expressões matemáticas. Assim, por exemplo, com respeito à idéia de que a geometria trataria de objetos ideais em oposição a outros que seriam os "reais", Wittgenstein escreve:

Geometria não é a ciência de planos geométricos, linhas e pontos, em oposição a alguma outra ciência de grosseiras linhas físicas, faixas e superfícies e as propriedades delas. A relação entre geometria e proposições da vida prática, sobre faixas, fronteiras de cores, bordas e cantos, etc., não é que as coisas de que a geometria fala, apesar de serem cantos e bordas ideais, parecem-se com aquelas faladas em proposições práticas; é a relação entre essas proposições e sua gramática. (2005, § 114, p 391)

\section{A SUGESTÃO DA "MEDIDA EXATA"}

Voltemos, uma vez mais, à sugestão de que haveria uma atividade, uma tarefa, a tarefa de "medir um círculo de raio 1" e que o sentido que estas palavras teriam seria o mesmo, tanto para o feito de Arquimedes, como para o que faziam as pessoas antes dele. Como vimos, essa proposta teria a vantagem de explicar o feito do grande matemático de maneira muito direta e natural: havia algo que chamávamos de "medição da circunferência de um círculo". Vários tentaram medir esse segmento e, por fim, Arquimedes finalmente teve sucesso. Ele conseguiu medir aquele círculo que outros já haviam tentado. Mas, o que diríamos a respeito de outras pessoas que também mediram círculos usando algum método empírico, como o barbante? Não teriam conseguido medir seus círculos? Por que não? 
que lhes teria "impedido"? Afinal, não poderiam eles usar um barbante (cortado do tamanho do raio) e tentar avaliar quantas vezes esse barbante cabia na circunferência? Neste ponto, costuma aparecer outra proposta para resolver o problema dos "dois tipos de medição", uma idéia que já mencionamos rapidamente antes, a idéia de "exatidão".

Segundo essa proposta, em ambos os casos teríamos executado uma medição. Tentamos não abrir mão disso. Apenas, no caso de uma medição matemática, teríamos uma medição "e$x a t a ”$, em oposição às medições empiricas (com barbantes, etc.), que seriam "meras aproximações". Já comentamos uma dificuldade inicial com essa solução. Não conseguiremos reservar as "meras aproximações" apenas para o caso das medições empíricas e as medições exatas, apenas para as medições matemáticas. Como vimos, gostaríamos de poder dizer também que o geômetra grego nos teria dado um método de obtermos aproximações de $\mathrm{P} i$, em oposição a medidas exatas (agora matemáticas), como a afirmação (matemática) de que o perímetro do hexágono é igual a seis lados. Nos encontraríamos, então, na situação constrangedora de termos de afirmar que Arquimedes mediu o círculo "exatamente" (em um certo sentido), e “apenas aproximadamente" (em um outro sentido).

Deixemos para um pouco mais adiante, porém, o problema de caracterizarmos esses dois sentidos da palavra "aproximação", sentidos esses capazes da estranha proeza de qualificar a medição de Pi proposta por Arquimedes, ao mesmo tempo, como sendo "exata" e "aproximada"! Antes disso precisamos examinar com um pouco mais de detalhes o método de cálculo por ele proposto. Esta exploração nos ajudará então a distinguirmos, mais ao final deste capítulo, dois sentidos para a palavra "aproximação" (o empírico e o matemático), da mesma forma que ocorrera no caso da palavra "medição". 


\section{O MÉTODO DE ARQUIMEDES PARA O CÁLCULO DE PI}

Nosso interesse em nos envolvermos na contribuição de Arquimedes é argumentarmos que essa se divide naturalmente em duas "metades", razoavelmente indepen-dentes. Começaremos expondo o que identificamos como a "primeira metade" da contribuição do geôme-tra. Arquimedes teria inventado um método para, a partir do lado de um polígono

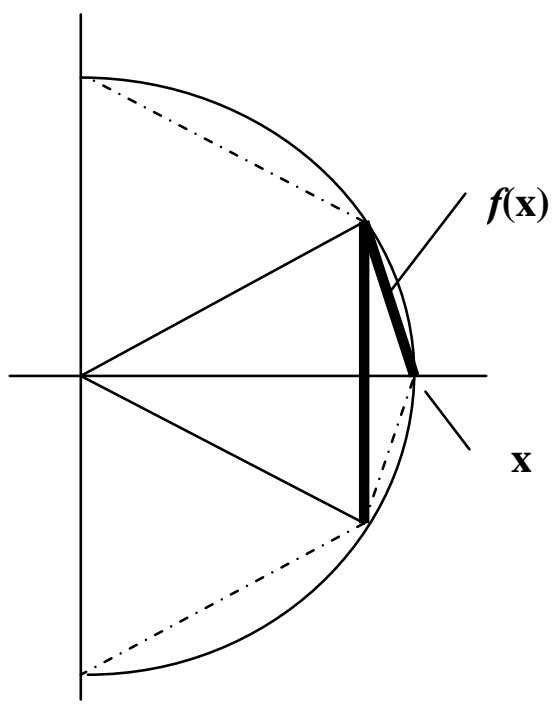
regular de $\boldsymbol{n}$ lados inscrito em um círculo, calcular o lado de um polígono (também regular e inscrito no mesmo círculo) de $\mathbf{2 n}$ lados. Em notação moderna, a função encontra-da pelo geômetra seria:

$$
f(x)=\sqrt{2-\sqrt{4-x^{2}}}
$$

(onde $\boldsymbol{x}$ é o lado do polígono de $\boldsymbol{n}$ lados e $\boldsymbol{f}(\boldsymbol{x})$ é o lado do polígono de $\mathbf{2 n}$ lados). Assim, dado um lado de qualquer $\boldsymbol{n}$ ágono (regular e inscrito em um círculo), o geômetra podia agora determinar o lado de um $\mathbf{2 n}$-ágono (inscrito no mesmo círculo).

O próximo passo de Arquimedes, então, (ainda nessa primeira "metade" de sua contribuição) foi escolher um polí- 
gono regular inicial para, a partir dele, ir calculando recursivamente os lados de polígonos com um número cada vez maior de lados, ou seja, cada vez com o dobro do número de lados do polígono anterior. Várias escolhas são possíveis para a base desse processo recursivo, sendo uma das mais simples a do hexágono regular inscrito em um círculo de raio 1 . Como sabemos, o lado dessa figura também é igual a 1, e assim podemos montar nosso método recursivo para encontrarmos o lado de qualquer polígono regular inscrito de $6.2^{n}$ lados como sendo:

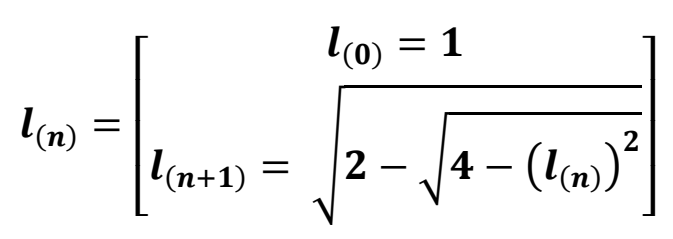

onde $I_{(n)}$ é o lado de qualquer $6.2^{n}$-ágono.

Uma vez de posse do lado de um $6.2^{n}$-ágono, podemos agora facilmente calcular seu perímetro, bastando, é claro, multiplicarmos $\boldsymbol{l}_{(\boldsymbol{n})}$ pelo número de lados. Assim, a partir da função acima, $\left[\boldsymbol{\lambda} \boldsymbol{n} \cdot \boldsymbol{l}_{(\boldsymbol{n})}\right]$, podemos montar uma outra função para calcularmos diretamente o perímetro, $\left[\boldsymbol{\lambda} \boldsymbol{n} \cdot \boldsymbol{P}_{\mathbf{6 . 2}} \boldsymbol{2}\right]$, de nossos $6.2^{n}$-ágonos. Teremos:

$$
P_{\left(6.2^{n}\right)}=6 \times 2^{n} \times l_{(n)}
$$

Assim, com $\left[\lambda \boldsymbol{n} \cdot \boldsymbol{P}_{\mathbf{6 . 2}}{ }^{\boldsymbol{n}}\right]$, temos um método, uma função, para calcularmos o perímetro de qualquer $6.2^{n}$-ágono, por maior que seja o $\boldsymbol{n}$, ou seja, por maior numero de lados que tenha o $6.2^{n}$-ágono.

Até aqui, tudo está bem. Mas, e daí? Seria essa a totalidade da realização de Arquimedes? Estaríamos sugerindo que tudo que Arquimedes fez foi descobrir um método de se calcular perímetros de $6.2^{n}$-ágonos? Até agora não falamos nada sobre 
círculos (salvo na caracterização de nossos 6.2 -ágonos como inscritos em um círculo de raio 1) e sequer mencionamos circunferência alguma, apenas perímetros de polígonos. $\mathrm{O}$ quê estaria faltando acrescentarmos à apresentação do método de Arquimedes, para chegarmos finalmente a um método de cálculo do valor de Pi que nos interessa? Dito de outra forma, qual seria a conexão entre o que expusemos até agora - essa função "[ $\left.\boldsymbol{\lambda} \boldsymbol{n} \cdot \boldsymbol{P}_{\mathbf{6 . 2}}\right]^{\boldsymbol{n}}$ "- e o cálculo do valor de $\boldsymbol{P} \boldsymbol{?}$.

Chegamos à segunda metade da contribuição de Arquimedes da qual falávamos no início desta seção. A resposta é obvia: Arquimedes usa a função $\left[\boldsymbol{\lambda} \boldsymbol{n} \cdot \boldsymbol{P}_{\mathbf{6 . 2}}\right.$ ] para obter aproximações (matemáticas) de Pi. Aí está, talvez, a real genialidade do geômetra grego. Poderíamos facilmente imaginar que o método, a função $\left[\boldsymbol{\lambda} \boldsymbol{n} \cdot \boldsymbol{P}_{\mathbf{6} .2^{n}}\right]$, já fosse conhecida e usada há muito tempo para calcular, por exemplo, o perímetro de polígonos com número par de lados a partir de lados de figuras mais simples ou com um número ímpar de lados. Com uma pequena alteração nas funções acima - partindo de uma base igual a $\sqrt{\mathbf{2}}$ - poderíamos ter uma função que calculasse os perímetros das sucessivas subdivisões dos lados de um quadrado, os $2^{n}$-ágonos. Mas, tais empregos do método recursivo que expusemos, ainda que tivessem sido comuns antes de Arquimedes, não alterariam em muito o calibre de sua contribuição.

Acompanhando Wittgenstein, podemos dizer que, ao usar $\left[\boldsymbol{\lambda} \boldsymbol{n} . \boldsymbol{P}_{\mathbf{6 . 2}} \boldsymbol{n}\right]$ para calcular $\boldsymbol{P} \boldsymbol{i}$, Arquimedes estabelece todo um novo uso, um novo sentido para aquele método recursivo, pois não podemos, por um instante sequer, confundir a contribuição de Arquimedes e o cálculo do valor de Pi com um mero método de cálculo de perímetro de polígonos, por mais engenhoso que esse possa ser. Mais uma vez, segundo Wittgenstein, poderíamos afirmar que Arquimedes de fato estabeleceu um novo símbolo, um novo cálculo, um uso completamente dife- 
rente para aquele método de cálculo de perímetros. Assim, se nos referimos ao método de cálculo de perímetros de $6.2^{n}$ ágonos como

$$
P_{6.2^{n}}=6.2^{n} \cdot l_{(n)}
$$

Poderíamos distinguir o novo cálculo, o novo uso que Arquimedes concebe para esse mesmo método, a ele nos referindo como:

$$
\pi=\lim _{n \rightarrow \infty} 6.2^{n} \cdot l(n)
$$

Podemos agora discriminar claramente os dois pontos fundamentais da contribuição de Arquimedes de que falamos acima: o primeiro ponto corresponde à invenção do método (1) de cálculo geral de perímetros e o segundo ponto seria o uso deste método para a aproximação de $\boldsymbol{P} \boldsymbol{i}$, ou seja, a nossa proposição (2).

Ainda que aceitemos o aparecimento de um novo símbolo, de um novo uso para (1), como quer Wittgenstein, ainda assim, em que exatamente consistiria, na opinião de filósofo, esse novo cálculo? A estratégia de Wittgenstein aqui é a de sempre: para respondermos essa pergunta, temos de discriminar os dois sentidos da palavra "medir" como já vínhamos fazendo e, mais importante do que isto, novamente discriminar dois sentidos da palavra "aproximação", um empírico e outro matemático. Uma vez separados estes dois sentidos para os dois termos - o sentido empírico e o matemático - podemos esclarecer então a ênfase de Wittgenstein no caráter normativo, como um "padrão de correção". 


\section{DOIS SENTIDOS PARA "MEDIÇÃO', DOIS SENTIDOS PARA "APROXIMAÇÃO'}

Retomaremos agora a nossa exposição de uma sugestão acima segundo a qual manteríamos a mesma idéia de "medição" nos dois casos (matemático e empírico), retorquindo que, no primeiro caso (matemático) Arquimedes mediu exatamente a medida do círculo. E, no segundo caso, o das medições empíricas, o mensurador obteria apenas resultados aproximados daquela (mesma) medida. Chegamos aqui a uma parte importante do argumento de Wittgenstein. Comecemos pelo relato de uma curiosidade histórica. O clímax da obra Sobre a medição do círculo, que contém a contribuição de Arquimedes, não é a apresentação de seu método, mas, estranhamente para os padrões modernos de matemática, a apresentação da seguinte aproximação de $P i$ :

$$
3 \frac{10}{71}<\pi<3 \frac{1}{7}
$$

Sua proposição número III (Arquimedes, 1952, p. 448) é exatamente a afirmação daquela desigualdade e o famoso método dos polígonos circunscritos é apresentado apenas como prova daquela proposição. Ora, na época de Arquimedes, já havia outras aproximações de $\mathrm{Pi}$. Em um conhecido livro de E.W.Hobson sobre a história de $\mathrm{Pi}$, somos informados de que os Babilônicos já usavam o número 3 como aproximação de $\mathrm{Pi}$, e que os egípcios usavam uma aproximação melhor, $\frac{\mathbf{2 5 6}}{\mathbf{8 1}}$ (HOBSON 1913, p. 13). Além disso, Hobson nos explica que a aproximação de 3 usada pelos babilônicos não era derivada de medições empíricas, mas baseada em argumento a priori, já conhecido na época, de que o lado de um hexágono inscrito é igual ao seu raio. 
Assim, podemos formar um quadro completo da situação destas expressões - "medição do círculo" e "medição aproximadas do cículo" - na época em que Arquimedes escreveu sua obra. Já fazia sentido, então, afirmarmos de alguém, digamos, que essa pessoa tinha medido a circunferência de um círculo (empiricamente). Além disso, também podíamos afirmar da medição empírica executada por alguém, que essa era "apenas aproximada", com isso nos referindo ao fato de que a pessoa, digamos, havia usado um barbante "grosso demais", ou talvez tivesse apenas avaliado "num golpe de vista" aquela medida. Por outro lado, podíamos falar em aproximações matemáticas de $\mathrm{Pi}$, como as aproximações de Babilônicos e Egípcios. E finalmente com Arquimedes, podíamos falar em medições matemáticas do valor de $\mathrm{Pi}$, em uma medição matemática dessa magnitude.

Ora, o importante aqui é que esses vários sentidos não se confundem. Assim, podemos dizer que Arquimedes mediu o círculo no sentido em que afirmamos que ele estabeleceu que:

$$
\pi=\lim _{n \rightarrow \infty} 6.2^{n} \cdot l(n)
$$

Por outro lado, podemos dizer que $\mathbf{3}$ e $\mathbf{3} \frac{\mathbf{1 0}}{\mathbf{7 1}}$ são aproximações matemáticas de $\boldsymbol{P} \boldsymbol{i}$, resultados de argumentos conduzidos de forma completamente a priori. Podemos falar também, em medições empíricas da circunferência (digamos, com um barbante) e, até mesmo, medições empíricas aproximadas da circunferência (digamos, feitas por um golpe de vista). Mas essas quatro noções não se misturam. Por exemplo, o cálculo de $\mathrm{Pi}$ de Arquimedes não era "aproximado" no sentido de "executado sem muito cuidado e rigor".

Vejamos mais cuidadosamente esses vários sentidos de "medir" e de "aproximação". Tomemos inicialmente as duas 
versões matemáticas, de "medições empíricas da circunferência" e "medições empíricas aproximadas da circunferência". Sabemos que a aproximação de Arquimedes que aparece em sua proposição III, $\mathbf{3} \frac{\mathbf{1 0}}{\mathbf{7 1}}$, também corresponde, é claro, ao perímetro de algum $6.2^{n}$-ágono. Para melhor distinguirmos as duas etapas da contribuição de Arquimedes poderíamos mesmo imaginar, como fizemos acima, que alguém, antes do tratado sobre o círculo, conhecesse o processo recursivo $\left[\lambda n . P_{6 . n^{2}}\right]$ e tivesse até mesmo usado o método de Arquimedes para chegar à mesma aproximação do geômetra grego, $\mathbf{3} \frac{\mathbf{1 0}}{\mathbf{7 1}}$. Porém, poderíamos perfeitamente imaginar que essa pessoa como tomando sua aproximação do valor de Pi como apenas "mais uma aproximação daquele valor", como o valor "3" que os Babilônicos usavam (que aliás, é uma aproximação de Arquimedes para $\mathbf{n}=0$ ). Claramente, uma pessoa assim não teria se dado conta do uso do algoritmo de Arquimedes como um método geral de se obter aproximações (cada vez melhores) de Pi. Em poucas palavras, essa pessoa não teria entendido $\left[\lambda n . P_{6 . n^{2}}\right]$ como:

$$
\pi=\lim _{n \rightarrow \infty} 6 \cdot 2^{n} \cdot l(n)
$$

Tal pessoa não teria feito o que Arquimedes fez, ainda que tivesse usado seu método para chegar à mesma aproximação que ele chegou! Se perguntássemos a ela qual seria a aproximação seguinte, provavelmente ela não entenderia do que estávamos falando. De uma pessoa assim não poderíamos dizer que ela tenha medido (matematicamente) o círculo. Poderíamos, no máximo, dizer que ela "encontrou uma boa aproximação usando um método muito engenhoso, método este que mais tarde seria usado por Arquimedes [...]”. Da mesma forma, não podemos dizer que os egípcios, ou babilônicos mediram $\mathrm{Pi}$ 
com suas aproximações de $\mathbf{3}$ e $\frac{\mathbf{2 5 6}}{\mathbf{8 1}}$, como dizemos que Arquimedes conseguiu. Exatamente por se tratarem de aproximações (matemáticas), não podemos dizer que $\mathbf{3}$ ou $\frac{\mathbf{2 5 6}}{\mathbf{8 1}}$, sejam uma medições de Pi.

Vejamos agora o uso empírico da palavra "aproximação". Imaginemos novamente que um fulano tenha medido a circunferência de um círculo com seu indefectível barbante. Aqui podemos afirmar que ele medira empiricamente o círculo. Mas nesse caso, supondo que tal Fulano tenha feito o processo todo com bastante cuidado, não há sentido em dizer que ele tenha medido aquele círculo apenas "aproximadamente". Por que qualificaríamos seu esforço assim, de "meramente aproximado"? É claro que poderíamos qualificar seu valor de "aproximado", ainda que a medição tivesse sido bem executada, usando como estalão uma aproximação matemática. Assim, por exemplo, poderíamos dizer que se o valor obtido por fulano não estivesse entre $3 \frac{10}{70}$ e $3 \frac{10}{71}$, sua medição (apesar de cuidadosa) não teria sido muito exata.

Chegamos, a essa altura, a mais um daqueles argumentos que Wittgenstein considera extremamente perigosos. $\mathrm{O}$ filósofo nos alerta contra esse argumento em vários trechos de seus escritos, sempre em tom de reprovação. Trata-se de uma tentativa de reintroduzirmos uma simetria entre aproximação matemática e aproximação empírica, argumentando que, assim como dizemos que toda a aproximação matemática não é exata (precisamente por se tratar de uma aproximação), também as medições empíricas seriam sempre e necessariamente aproximações, não importando seu resultado, não importando o cuidado com que tenham sido feitas. Diríamos que qualquer processo de medição, por maior que fosse o esmero técnico em sua condução, seria apenas e sempre "meramente aproxima- 
do", simplesmente porque "toda medição empírica é aproximada".

Suponhamos que antes da época de Arquimedes, alguém tivesse executado aquele grande projeto de pesquisa e tivesse medido o valor de $\mathrm{Pi}$ usando um círculo de vários quilômetros. Que sentido haveria, após terminado o trabalho todo, antecipadamente sentenciarmos sua medição como sendo "apenas aproximada”? Por que não poderia ser ela exata? É claro que, no caso específico de $\mathrm{Pi}$, quando muitos anos mais tarde obtemos a prova matemática de sua irracionalidade ${ }^{2}$, passaria a fazer sentido afirmarmos que uma medida empírica de Pi não pode ser exata. Ou, como certamente preferiria Wittgenstein, uma declaração que envolvesse a idéia de uma "medição exata de Pi" passaria a ser tomada como um indício de falta de familiaridade com a matemática moderna. Mas, por que não poderíamos dizer que, se desenhamos um hexágono de diâmetro de comprimento $\mathbf{1}$ e, ao medirmos seu perímetro, encontramos 6, encontramos empiricamente o comprimento exato daquele perímetro?

$\mathrm{Na}$ ausência de um argumento assim, distinguindo "medidas" racionais e irracionais, o que estaríamos querendo dizer quando simplesmente caracterizamos em geral as medições empíricas como sendo "apenas aproximações", grosserias "cópias empíricas de idéias abstratas”? Poderíamos estar nos referindo, é claro, a algum outro critério, uma outra técnica de medição, como por exemplo, a medição do número de marcas que uma roda deixaria em um longa estrada. Dividiríamos então o comprimento total do percurso pelos números de intervalos e teríamos uma medição de $\mathrm{Pi}$. E poderíamos dizer que essa medição é melhor do que a outra, pois lançaria mão de um círculo muito grande (assim como dizemos que uma medição feita com uma régua apenas com marcações de centíme- 
tros é pior do que uma feita com uma que tenha marcações em milímetros). Mas o que estaríamos tentando dizer quando afirmamos que todas as medições empíricas são necessariamente inexatas? Inexatas em relação $a$ quê?

$\mathrm{Na}$ melhor das hipóteses estaríamos apelando para uma maneira estranha de sublinharmos o caráter empírico dessas medições. Mas, então, novamente o filósofo sugeriria reformularmos nossa distinção em termos de uso das expressões, sem confundir a sentido desses termos quando usados em afirmações empíricas, com esses (mesmos) termos no interior de afirmações matemáticas (as "regras”). Não deveríamos falar de uma medição "ideal" que seria "exata" e frente à qual todas as medições "reais" seriam "aproximadas". Ao invés disso, Wittgenstein sugere que, nesses casos empíricos, a idéia de exatidão absoluta de uma medida (não exatidão relativa, de um par de medições) sequer faria sentido. Isso aconteceria em contraste com o caso de quais outras expressões? Não faria sentido esse sentido absoluto como no caso das afirmações matemáticas. Nosso resultado final, longe de ser uma aproximação das noções de "medições empíricas" e de "regras matemáticas", sublinharia mais uma vez a imensa diferença conceitual entre essas duas expressões.

Wittgenstein aborda as distinções gramaticais entre esse par de conceitos - "aproximação matemática” e "aproximação empírica" - em vários pontos de sua obra:

O que a palavra "exatidão" significa? Será exatidão real se você devesse chegar para um chá às 4:30 e entrasse quando um relógio bate 4:30? Ou só teríamos exatidão se você começasse a abrir a porta no momento que o relógio começasse a bater? Mas como esse momento deveria ser definido, e como deveria "começar a abrir a porta" ser definido? Seria correto dizer-se, "É difícil de dizer o que seria exatidão real, já que tudo o que conhe- 
cemos são apenas aproximações grosseiras"? (WITTGENSTEIN L. 1960, p. 81)

No final de uma discussão nas Investigações Filosóficas exatamente paralela à citação acima, do Brown Book, o próprio Wittgenstein responde sua pergunta:

Nenhum ideal único de exatidão foi estabelecido: não sabemos o que deveríamos imaginar sobre esse título - salvo se você mesmo estabelecer o que deve ser chamado assim. (WITTGENSTEIN L. 2001, p. 36)

Resumindo o que obtivemos até agora, podemos dizer que babilônicos e egípcios tinham aproximações matemáticas de $\mathrm{Pi}$, mas não que tenham matematicamente medido a circunferência do círculo, como fez Arquimedes, exatamente por se tratarem de aproximações. Por outro lado, podemos dizer que alguém empiricamente mediu um círculo (com nosso barbante), mas, nesse caso, sua medida não seria aproximada, salvo em um sentido reprovador, comparando-a com outra medição mais cuidadosa ou, o que nos interessa mais, em relação a uma aproximação matemática.

\section{A CONTRIBUIÇÃO DE ARQUIMEDES, SEGUNDO WITTGENSTEIN}

Podemos retornar ao problema com o qual iniciamos nossa reconstrução: em que consistiria a contribuição de Arquimedes? Havíamos sugerido que sua contribuição era a descoberta de uma medida, a medida da circunferência de um círculo de raio 1. Essa maneira de expormos o problema tinha a grande vantagem de simplificar muito nossa apresentação do problema. Durante todo o tempo, falávamos diretamente sobre medidas. As pessoas mediam círculos antes de Arquimedes, 
vários tentaram, e, finalmente, o matemático grego chegou à sua famosa medida. O problema com essa forma de exposição é, como vimos, uma mistura entre significados empíricos e matemáticos de expressões como "medida". Assim, se por um lado nossa proposta simplificava muito nossa exposição do que Arquimedes fez, por outro, aproximava aquela proposta perturbadoramente de conquistas completamente diferentes e muito menos importantes. Não gostaríamos de ter que abdicar da fronteira entre a conquista de Arquimedes e uma medição qualquer, executada com um barbante sobre um círculo traçado em um papel. O grande geômetra não fez apenas mais uma medição do círculo, como tantos haviam feito antes dele. Sua medição era diferente das outras.

Nesse ponto, acabamos topando com um novo ingrediente em nossa discussão: a idéia de exatidão. Propusemos então uma solução para distinguirmos o feito de Arquimedes de uma medição empírica qualquer. Continuávamos afirmando que ele teria medido o círculo, no mesmo sentido do que muitos haviam feito antes dele, apenas o teria feito exatamente, em oposição às outras medições anteriores que seriam meras "aproximações". Novamente tivemos problemas. Gostaríamos de afirmar que, em contraste com uma medição matemática como a do perímetro de um hexágono, a medição de Arquimedes só nos fornecia aproximações. Mas isto ameaçava borrar, mais uma vez, a distinção entre o feito de Arquimedes e qualquer medição empírica do círculo. Havíamos dito que as medições empíricas eram apenas aproximadas. Mas agora, em contraste com o caso do hexágono, gostaríamos de qualificar a medição de Arquimedes como nos fornecendo também, mas em um outro sentido, apenas aproximações.

A solução de Wittgenstein se dá novamente distinguindo dois sentidos para a palavra "aproximação", um matemático e 
outro empírico, da mesma forma que havíamos feito para a noção de medida. Assim, o número $\mathbf{3}$ dos babilônicos, apesar de ser um valor muito grosseiro para $\mathrm{Pi}$, era usado como uma aproximação matemática, por ser igual ao perímetro do hexágono. Assim, podíamos afirmar que era uma medida aproximada de $\mathrm{P} i$, não porque tivesse sido mal executado, ou porque tivéssemos dúvidas a seu respeito, mas porque esse valor, apesar de próximo, necessariamente era diferente de $\boldsymbol{P} \boldsymbol{i}$.

Chegamos ao núcleo da sugestão de Wittgenstein. A contribuição de Arquimedes não fala diretamente sobre uma medida (empírica), nem sequer fornece uma aproximação de uma medida (empírica). O que o geômetra nos ofereceu foi um novo critério geral para determinarmos o sentido de alegações da proximidade de pares de medições (empíricas) do círculo. Ou seja, seu método nos fornece uma cota superior e uma cota inferior para essas medições (empíricas). E aqui é importante lembrarmos nossa divisão de sua contribuição em duas partes, pois ela nos dá a chave para o seu real mérito. Mais do que apenas nos fornecer um método geral para encontrarmos a medida (exata) de perímetros de $6.2^{n}$-ágonos, o que seria apenas a primeira metade de seu feito, Arquimedes propôs um uso completamente diferente para seu algoritmo. Usaríamos aquele algoritmo, não como um método geral para encontrarmos medidas matemáticas (de perímetros de polígonos), mas como um método igualmente geral para encontrarmos aproximações matemáticas de Pi. E, por fim, ainda segundo Wittgenstein, usaríamos essas aproximações matemáticas para julgarmos o sentido (ou não) de alegações de uma maior exatidão de uma medição empírica sobre outra.

Poderíamos, a título de conclusão, imaginar uma situação extrema. Alguém, lançando mão das técnicas mais complicadas e sofisticadas possíveis, encontra uma medida (empírica) para a 
circunferência de um circulo e outra pessoa, apostando apenas em seu golpe de vista e em sua sorte, encontra outra medida. Usando nossa nova técnica de "aproximações matemáticas", ainda que a medição do primeiro possa parecer mais exata do que a do segundo, se encontrarmos um intervalo que contenha a segunda medição, mas não a primeira, nosso veredicto será implacável: a segunda medida é mais exata do que a primeira. De nada adiantaria insistirmos nos cuidadosos detalhes que foram levados em conta na primeira medição. Qualquer alegação de erro no julgamento da exatidão relativa das duas medidas teria de necessariamente passar pela indicação de um erro na execução do algoritmo de Arquimedes.

Daí podermos afirmar de forma mais precisa que, com Arquimedes, passamos a usar a execução (correta) de seu algoritmo como critério julgador de alegações sobre a exatidão relativa de medições empíricas. Nas palavras do próprio filósofo:

Se tomo a construção [da bisseção de um ângulo] como meu critério, de jeito nenhum posso checar os ângulos medindo-os. Seria muito mais o caso de: se a medição der uma diferença, direi: "O compasso estava ruim, aquilo não era uma linha reta, etc. Pois a construção é agora meu padrão de acordo com o qual julgo a qualidade da medição. (WITTGENSTEIN L. 1979, p. 205)

\section{COMENTÁRIOS FINAIS}

Iniciamos nosso artigo mencionando duas teses terrivelmente contra-intuitivas propostas por Wittgenstein em sua filosofia da matemática. A primeira dessas teses - da "mutação semântica das provas" - afirma que nunca logramos confirmar (ou infirmar) nenhuma conjectura matemática porque, na opinião do filósofo, o advento da prova envolve sempre uma alteração no próprio sentido dos termos envolvidos na conjectu- 
ra original. A segunda tese, igualmente estranha - a tese da nãopredicatividade das regras - afirma que, ao contrário do que normalmente pensamos, a matemática jamais deve ser entendida como falando sobre objetos, objetos esses que deveriam ser entendidos como sendo "abstratos", em contraste com os objetos empíricos ordinários, os corpos.

A matemática não falaria sobre objetos, sejam eles empíricos ou abstratos. As proposições matemáticas seriam regras para julgarmos alegações empíricas, descartando certas alegações como sendo "absurdas". Como afirmamos em nossa introdução, as duas estranhas teses de Wittgenstein tem uma estreita conexão entre si. Em poucas palavras poderíamos dizer que, é porque imaginamos que a matemática fale sobre objetos (abstratos) que nos deixamos iludir imaginando também que as regras matemáticas respondam às conjecturas anteriores: a aproximação entre o sentido dos termos antes e depois da prova é justamente levada a cabo pela postulação de objetos ("ideais") que funcionam como pivôs, conectando os dois momentos. Tudo isso, no entender do filósofo, seria apenas o resultado de uma aproximação enganadora (uma "irreführende Analogie") entre contextos de aplicação empíricos e regras matemáticas contendo os mesmos termos. As regras matemáticas não falam diretamente sobre a realidade, nenhuma realidade, como uma realidade platônica abstrata de objetos ideais. As regras matemáticas estabelecem novos critérios para o emprego de termos antigos, alterando assim, seus sentidos. Mais uma vez, nas palavras do filósofo.

Pode-se também exprimir-se de forma grosseira dizendo-se que proposições matemáticas contendo certo símbolo são regras para o uso daquele símbolo, e que esses símbolos podem agora ser usados em afirmações não matemáticas. (WITTGENSTEIN 1976, p. 33) 
Ao longo desse artigo não pretendemos ter mostrado mais do que um caminho para oferecer alguma razoabilidade a essas estranhas teses e, ainda assim, atacando, não o problema em toda a sua generalidade, mas nos restringindo a um caso matemático específico, a famosa medição arquimediana da circunferência.

Abstract: Wittgenstein's philosophy of mathematics involves two highly controversial theses: the idea that mathematical propositions are not about (abstract) objects and the idea that no mathematical conjecture is ever answered as such, because the advent of the proof always determines a semantical shift of the meanings of the terms involved in the conjecture. The present article offers a reconstruction of Wittgenstein's arguments supporting these theses within a very restricted setting: Archimedes' discovery of an algorithm for calculating the number $P i$.

Key-words: Wittgenstein; Philosophy of mathematics; continuity.

\section{NOTAS}

1 Esse ponto distingue claramente Wittgenstein de um Intuicionista. Apesar desse último não aceitar, como o clássico, uma concepção de "verdade matemática" como sendo logicamente independente da idéia de "demonstração", por outro lado, para um construtivista assim, a própria noção de "prova" envolveria a determinação antecipada das condições que objeto deveria satisfazer para esse poder ser uma demonstração de uma dada proposição.

2 Obtida por J. H. Lambert em 1768 (Wikipedia, The free Encyclopedia) 


\section{REFERÊNCIAS}

ARQUIMEDES. Measurament of the Circle. In: Euclid, Archimedes, Apollonius of Perga, Nicomachus. Chicago: Great Books, Encyclopaedia Britannica, Inc, 1952.

HOBSON, E. W. Squaring the Circle: a history of the problem. Cambridge: Cambridge University Press, 1913.

WIKIPEDIA, The free Encyclopedia. (s.d.). Pi. Acesso em 2009, disponível em http://en.wikipedia.org/wiki/Pi

WITTGENSTEIN, L. Philosophical Investigations. Oxford: Blackwell Publishing, 2001. 2005.

. The Big Typescript: TS 213. Oxford: Basil Blackwell,

. The Blue and The Brown Books. Nova Iorque: Harper Torchbooks, 1960.

. Wittgenstein and the Vienna Circle. Oxford: Basil Blackwell, 1979.

. Wittgenstein's Lectures on the Foundations of Mathematics, Cambridge, 1939. Chicago: The University of Chicago Press, 1976. 